\title{
基于遥感数据的小水库塘坝拦洪计算方法研究与 应用
}

\author{
曹明亮 ${ }^{(1)}$ ，周惠成 ${ }^{(1)}$ ，张弛 ${ }^{1}$ ，张爱静 ${ }^{(1)}$, 杨扬 ${ }^{(1)}$ \\ (1) 大连理工大学水利工程学院, 大连 116024 ; \\ (2) 四川省水利水电勘测设计研究院, 成都 610072 \\ *E-mail: hczhou@dlut.edu.cn
}

收稿日期: 2010-10-15; 接受日期: 2011-04-01

国家自然科学基金(批准号: 50809010, 50909012, 51079014)和 “十一五” 国家科技支撑计划课题(批准号: 2007BAB28B01)资助项目

\begin{abstract}
摘要本文以美国陆地资源卫星“Landsat TM/ETM+"数据为基础，以流域地形分类为手段， 以降雨蒸发为控制条件, 提出了基于遥感数据的小水库塘坝拦洪计算方法. 该方法旨在利用遥 感技术研究解决小型水利工程影响流域洪水预报精度的问题, 主要针对上游有众多小型水利 工程的流域, 也可用于无径流资料的小型水库径流估算. 以 20060826 洪水为例, 对 19 个有资 料小水库进行拦洪模拟发现, 拦洪总量绝对误差为 -0.2 万 $\mathrm{m}^{3}$, 相对误差为 $-0.12 \%$, 模拟精度较 好. 使用此方法对全流域的小水库塘坝进行拦洪计算, 并校正原洪水预报方案, 校正后的相对 误差由校正前的 31.8\%降低到 10.1\%，精度明显提高.
\end{abstract}

关键词 遥感信息 小水库塘坝 拦洪计算

\section{1 引言}

洪水预报是水库调度的基础，对于上游建有众 多中小水利工程的大型水库来说, 不断修建的水利 工程使径流过程发生了改变, 致使不能反映这一变 化的洪水预报模型难以满足精度要求. 若前期久旱 无雨, 降雨后大部分地表径流会被中小水库、塘坝等 工程拦截, 造成实际洪量小于预报值. 用原预报值作 决策就可能使水库提前或加大泄流, 一旦此后无大 的径流过程, 将对水库来年的供水、发电等兴利效益 的发挥带来严重的影响; 若前期降雨较充足, 一旦再 降大雨, 流域内的塘坝等小型水利工程可能出现泄 流或溃坝情况, 使预报洪量严重偏小, 从而对水库的 防洪安全产生威胁, 使调度处于非常被动的局面. 因
此, 流域洪水预报中考虑中小水利工程拦洪或泄洪 等人类活动影响显得十分必要. 由于中型水库的运 行资料比较容易获得, 小水库塘坝数量多、分布广, 不易完全掌握运行资料, 因此本文以小水库塘坝为 研究重点.

就目前国内外学者的研究成果来看, 研究重点 主要集中在人类活动对长时间尺度流域水循环的影 响 $^{[1-12]}$, 而对考虑人类活动影响的洪水预报研究得较 少. 后者主要分为两个方面: 一为研究人类活动影响 下的洪水属性变化, 如 Pinter ${ }^{[13]}$ 和 Brath $^{[14]}$ 分别用数 理统计及水文模型的方法研究了人类活动对洪水频 率的影响; 二为研究人类活动影响下的水文模型参 数率定方法, 如程春田、王本德 ${ }^{[15]}$ 提出了考虑人类活 动影响的流域水文模型参数的确定方法, 并将其应 
用于石头口门水库; 郭生练等 ${ }^{[16]}$ 在新安江三水源产 流模型和纳西及地下线性水库汇流模型的基础上, 提出了考虑水利工程和土地利用对产汇流机制影 响的洪水预报方案. 对于上游建有众多中小水利工 程的大型水库, 上述研究方法仅能通过经验确定人 类活动的影响量, 再以此影响量确定模型参数, 不能 反映人类活动的影响过程, 并且由于模型结构与 模型参数的不确定性, 计算结果也存在很大的不确 定性.

遥感是在 20 世纪 60 年代初发展起来的一门新兴 技术，具有获取信息的速度快、周期短、范围广、信 息量大等特点，目前已广泛应用于农业、地质、气象、 水文、环保等领域. 本文以美国陆地资源卫星“Landsat TM/ETM+" 数据为基础, 在已有研究成果的基础上, 提出了基于遥感数据的流域小水库塘坝拦洪计算方 法. 该方法首先通过遥感资料与水库运行资料建立 水面面积库容相关关系, 然后根据降雨蒸发情况分 析小水库塘坝库容的变化, 并得到对应洪水时段的
拦洪量. 利用此拦洪量与大中型水库的实测拦洪量 之和，对原洪水预报模型进行校正，可为受影响大型 水库的洪水预报提供数据支持.

\section{2 所选典型流域概况}

丰满水库位于吉林省东南部的第二松花江上, 控制流域面积 $42500 \mathrm{~km}^{2}$. 为便于水库预报工作, 将 丰满流域划分为三个区: 丰满水库蓄水区(I 区)、五道 沟以上(II 区)与白山水库以上(III区). 2006 年的流域 调查显示, II 区内共有大型水库 1 座, 中型水库 12 座, 小一型水库 86 座(其中 23 座有运行资料), 小二型水 库 390 座, 塘坝则无以计数, 中小水利工程总库容为 6.42 亿 $\mathrm{m}^{3}$, 占全流域中小型水利工程总库容 7.05 亿 $\mathrm{m}^{3}$ 的 $91 \%$. 近年的洪水预报实践表明，对于一些洪 水, II 区内小水库塘坝的拦洪或泄洪作用明显, 因此 本文以丰满 II 区作为典型流域开展研究, 其流域内 水系、水库与站点情况如图 1 所示.

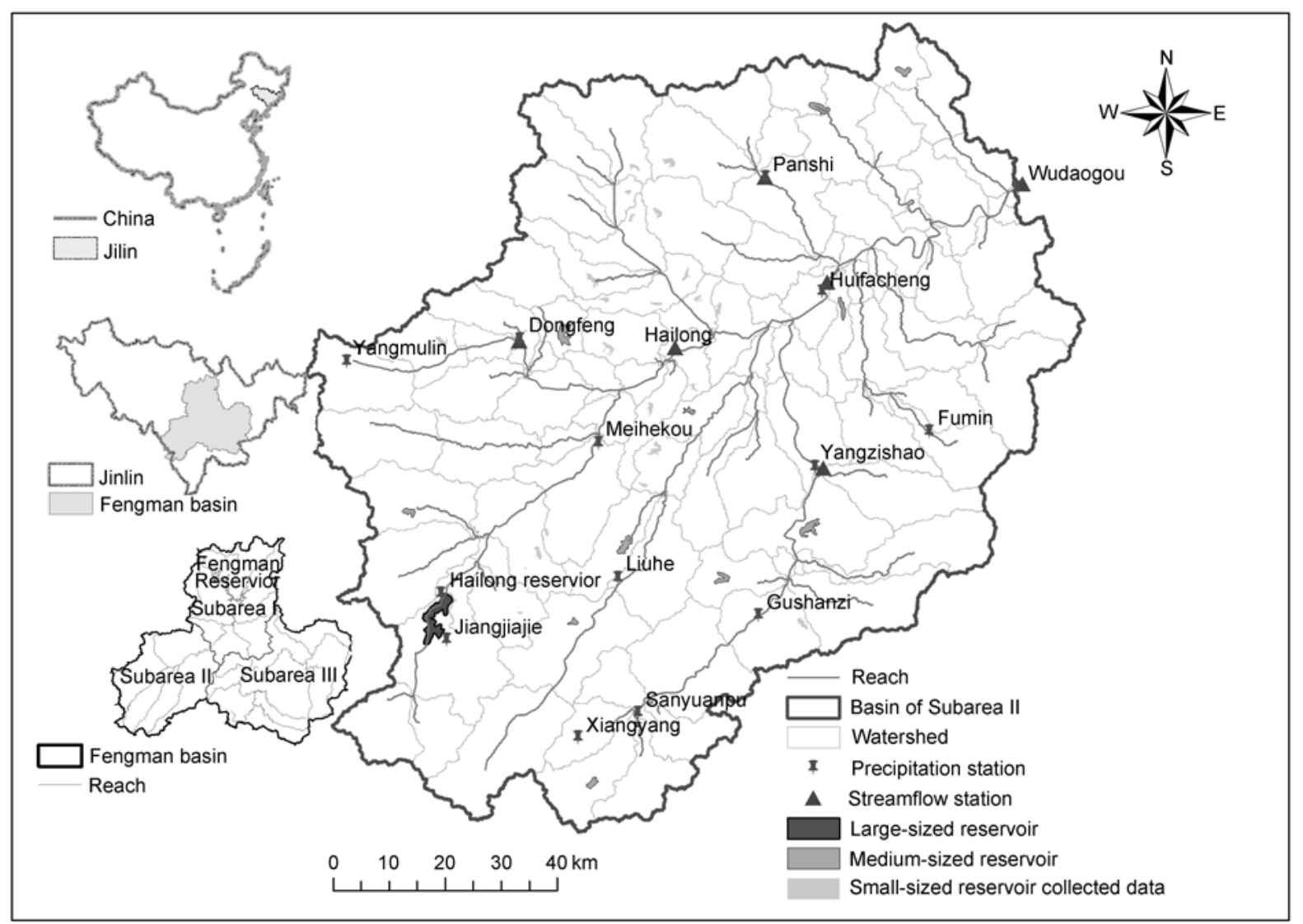

图 1 丰满 II 区流域图 


\section{3 资料}

\section{1 水文气象资料的收集与处理}

本文所用水文气象数据如表 1 所示. 按水库分布 情况, 利用中国科学院计算机网络信息中心国际科学 数据镜像网站(http://datamirror.csdb.cn)提供的 $90 \mathrm{~m}$ DEM 数据将丰满 II 区分为 101 个子流域(图 1). 各子 流域的降雨采用就近雨量站的实测数据, 最大蒸发 能力根据梅河口气象站的气象数据采用彭曼公式 ${ }^{[17]}$ 计算. 各小水库塘坝的降雨蒸发资料直接采用其所 在子流域的数据.

\section{2 遥感资料}

Landsat 是美国陆地资源卫星系统. 从 1972 年开 始发射第一颗卫星 Landsat 1 至今, 共发射了 7 颗. 目 前应用最广的是 Landsat 4-5 的 TM 数据与 Landsat 7 的 ETM+数据, 其重复周期为 16 天, 每景影像覆盖面 积为 $185 \mathrm{~km} \times 185 \mathrm{~km}$. 本文所用的 $\mathrm{TM} / \mathrm{ETM}+$ 数据由 地球系统科学数据共享网 (http:// www.geodata.cn)与 中国科学院计算机网络信息中心国际科学数据镜像 网站(http://datamirror.csdb.cn), 其中 2003 年以后的 $\mathrm{ETM}+$ 数据由后者进行去条带处理.

研究流域位于 4 个轨道遥感图像的交接处(图 2). 由于 23 个有资料小型水库中有 19 个分布在轨道号为 p118r30 的遥感图像覆盖范围内, 因此本文以该范围 为研究对象, 计算小水库塘坝对洪水的拦蓄作用. 已 有遥感数据清单如表 2 所示, 其中每一景遥感数据都 可用于建立小水库库容与面积的对应关系, 对一次 洪水的多景遥感数据可用于分析相应洪水的小水库 拦洪量.

\section{4 基于遥感数据的小水库塘坝拦洪计算方 法}

\section{1 研究的总体思路}

本文首先针对有资料的小水库，通过地形分类 及水面信息获取, 建立各类型小水库的面积库容相 关关系 ${ }^{[18]}$ (由于小水库与塘坝的地形特征相似, 该相 关关系也适用于塘坝). 再以两景遥感数据的水面信 息为基础, 通过分析时段内的降雨蒸发, 计算小水库 塘坝逐日的水面面积变化, 并将其转化为库容的变 化, 洪水时段内小水库塘坝库容的变化即为拦洪量. 最后进行拦洪量验证与应用. 本文的总体思路如图 3 所示.

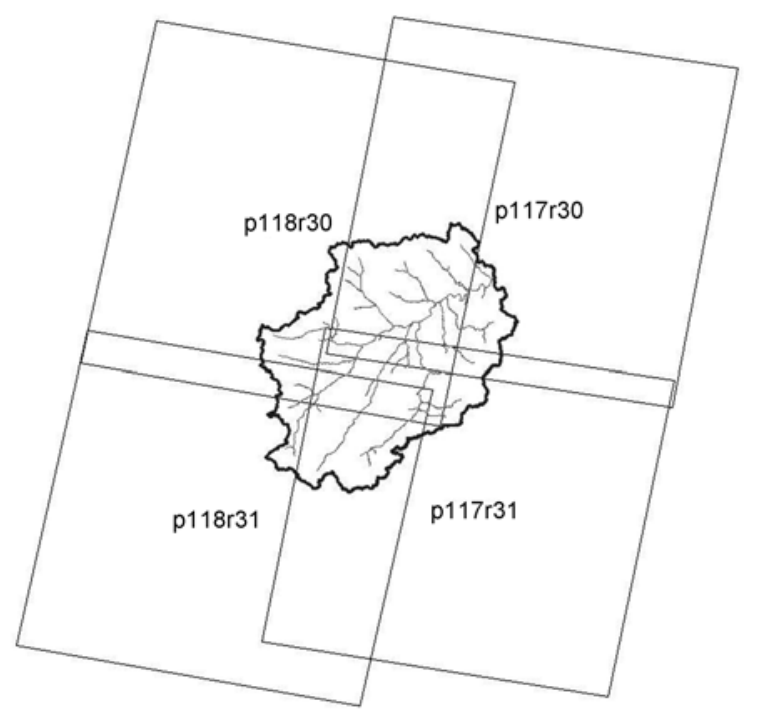

图 2 丰满 II 区的遥感数据覆盖情况

\section{表 1 丰满 II 区水文气象资料}

Variable

Precipitation Daily precipitation for 1993-2006 from 14 precipitation stations

Runoff Daily streamflow data for 1993-2006 from Wudaogou station

Reservoir Daily water level, reservoir storage, reservoir inflow for 1993-2006 in flood season from 1 large reservoir, 12 middle-sized

operation reservoirs and 23 small reservoirs

Meteorology Daily temperature, wind speed, relative humidity and solar radiation for 1993-2006 from Meihekou weather station

表 2 轨道号为 p118r30 的遥感数据清单

\begin{tabular}{cccccccccc}
\hline Year & 1993 & 1996 & 1999 & 2000 & 2001 & 2002 & 2003 & 2005 \\
\hline & $1993-9-7$ & $1996-8-30$ & $1999-10-18$ & $2000-4-11$ & $2001-9-21$ & $2002-4-1$ & $2003-8-26$ & $2005-9-8$ & $2006-8-18$ \\
Date & & & & $2000-5-13$ & & $2002-5-19$ & $2005-10-18$ & $2006-9-19$ \\
& & & & $2000-9-18$ & & $2002-9-24$ & \\
& & & & & \\
\end{tabular}




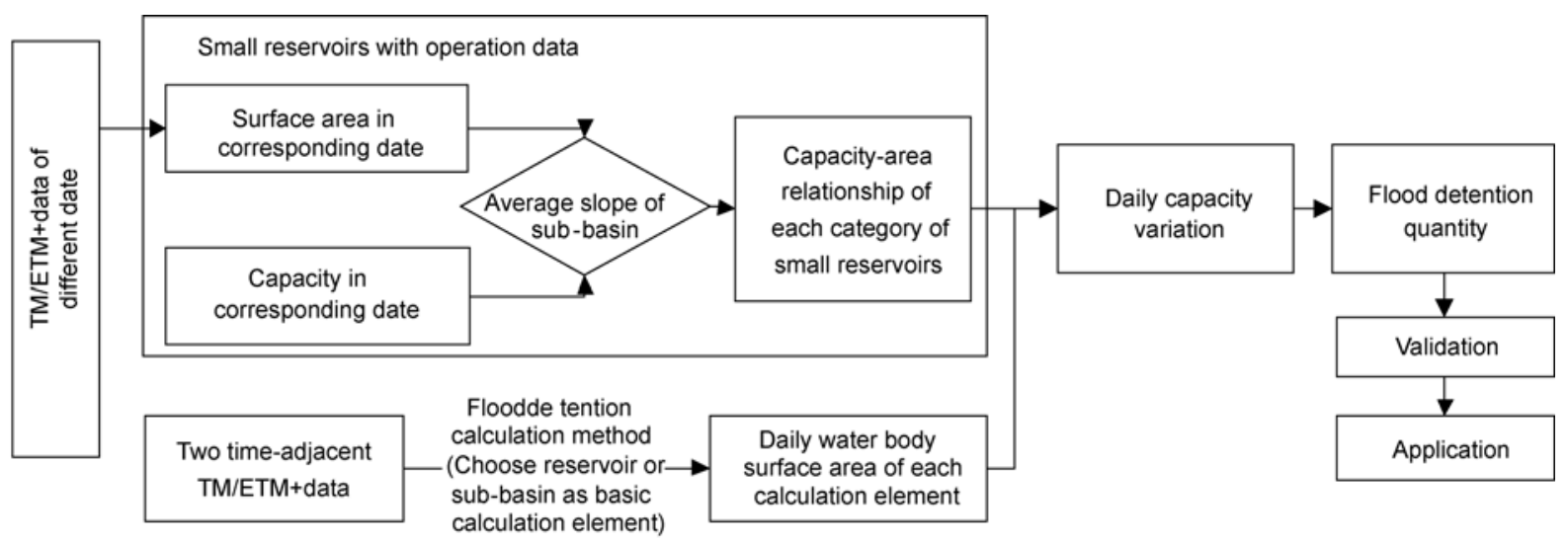

图 3 小水库塘坝拦洪计算的技术路线图

\section{2 基于 TM/ETM+数据的水系提取方法}

目前关于水系提取的方法较多, 主要有单波段

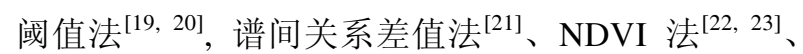
NDWI 法 ${ }^{[24-26]}$. 本文采用改进的谱间关系法, 该方法 利用水体在 TM2 和 TM3 波段上的反射率与滩涂、山 体阴影存在较大差异, 在 TM4 和 TM5 波段上反射率 较小, 与其它地物区别明显的特征, 通过模型 $\frac{T M 2+T M 3}{T M 4+T M 5}$ 进行图像增强, 再选取合适的阈值来实 现水体信息的提取. 具体的模型为

$$
\frac{T M 2+T M 3}{T M 4+T M 5}>k 2,
$$

其中 $k 2$ 为提取水体的阈值, $k 2 \in[1,2]$, 由于各景遥感 数据的辐射能量不同, 本文中不同时相 $k 2$ 的取值根 据所提取水体的拟合程度确定, 取值范围为 [1.4, $1.6]$.

\section{3 小水库塘坝拦洪计算方法}

Sawunyama ${ }^{[27]}$ 以 Limpopo 流域的 8 个小水库为 控制点, 提出了小水库入流计算方法并计算了各水 库的入流过程. 本文根据丰满 II 区的具体情况, 对计 算方法进行了改进, 改进后的方法不用获得小水库 塘坝的精确位置信息, 便可计算全流域小水库塘坝 的拦洪量, 具体计算方法如下.

1) 选取汛期质量较高的两景遥感数据, 将其间 隔时段作为计算时段.

2) 选择水库或者子流域为基本计算单元, 选择 有资料小水库用于计算方法验证, 选择子流域推求
所有小水库塘坝的拦洪量.

3) 针对上述基本计算单元, 比较由两景遥感数 据提取的水面面积, 设前期的水面面积为 $A_{\mathrm{res}, \tau-n}$, 后 期的水面面积为 $A_{\mathrm{res}, \tau}$. 若 $A_{\mathrm{res}, \tau}>A_{\mathrm{res}, \tau-n}$, 则说明时段 内计算单元拦蓄了部分洪水; 反之, 则处于泄洪状态. 其中 $n$ 表示两景数据的时间间隔, $\tau$ 与 $\tau-n$ 表示数据获 取时间.

4) 时段内各单元逐日水面面积的计算:

若 $A_{\mathrm{res}, \tau}>A_{\mathrm{res}, \tau-n}$, 则

$$
A_{\mathrm{res}, t}= \begin{cases}A_{\mathrm{re}, t-1}+\frac{N}{n}\left(A_{\mathrm{res}, \tau}-A_{\mathrm{res}, \tau-n}\right), & \text { "wet days", } \\ A_{\mathrm{re}, t-1}, & \text { "dry days", }\end{cases}
$$

其中 $t$ 表示计算时段内的天数, $t \in[1, n]$;

wet day 的判定条件为

$$
\text { “wet days" }=\left(\sum_{i=t}^{t-10} P_{i}>x\right) \wedge\left(P_{t}-E_{\mathrm{pot}_{t}}>0\right),
$$

其中 $\sum_{i=t}^{t-10} P_{i}$ 表示前 10 日累积降雨; $x$ 为待率定的参数, 在本文中取 $8 \mathrm{~mm}$.

$$
\begin{aligned}
\text { 若 } A_{\mathrm{res}, \tau}<A_{\mathrm{res}, \tau-n}, \text { 则 } \\
A_{\mathrm{res}, t}=\left\{\begin{array}{l}
A_{\mathrm{res}, t-1}, \\
A_{\mathrm{res}, t-1}-\frac{n-N}{n}\left(A_{\mathrm{res}, \tau-n}-A_{\mathrm{res}, \tau}\right) .
\end{array}\right.
\end{aligned}
$$

5) 利用水库面积库容相关关系, 计算得各单元 的逐日库容, 比较对应洪水时段的水库库容变化, 可 得各计算单元的拦洪量. 


\section{5 计算结果分析及应用}

\section{1 小水库塘坝分类}

根据小水库塘坝所处子流域的平均坡度, 将其 分为 3 类, 分类标准及各类包含的有资料小水库的数 量如表 3 所示.

\section{表 3 小水库塘坝分类标准及有资料小水库分类结果}

\begin{tabular}{cccc}
\hline & \multicolumn{3}{c}{ Category } \\
\cline { 2 - 4 } & I & II & III \\
\hline The threshold of average slope & $\leqslant 3 \%$ & $(3 \%, 5 \%]$ & $>5 \%$ \\
$\begin{array}{c}\text { The number of small reservoirs } \\
\text { with operation data }\end{array}$ & 3 & 10 & 6 \\
\hline
\end{tabular}

\section{2 不同类别小水库塘坝面积库容相关关系的建} 立

分析时首先进行数据质量检查, 主要包括两个 方面: 一是遥感数据质量的检查, 二是小水库实测资 料质量检查. 前者主要是检查云层对水面信息提取 的影响, 由于可获得的遥感数据有限, 而相关关系的 建立又要求尽可能多的样本, 因此本文对所有可用 遥感数据进行计算, 再从中剔除受云层影响的水库 的水面信息; 后者主要是检查小水库实测数据的质 量. 与大中型水库不同, 不同地区的小水库在管理制 度与管理水平上存在很大差异, 使实测运行资料的 精度存在一定的问题, 部分小水库即使对于场次洪 水过程也没有完整的库容变化记录. 进行数据质量 检查后, 采用精度可靠的数据计算得各类别小水库 面积库容相关关系如表 4 与图 4 所示.

\section{3 小水库拦洪计算验证}

由于所有遥感数据中仅 2006 年的 2 景数据处于

\section{表 4 各类小水库面积库容相关关系}

\begin{tabular}{cccc}
\hline $\begin{array}{l}\text { Reservoir } \\
\text { categories }\end{array}$ & Capacity-area relationship & $\begin{array}{c}\text { Number of } \\
\text { samples }\end{array}$ & $R^{2}$ \\
\hline I & $\log (V)=1.2359 \log (A)-1.1728$ & 10 & 0.92 \\
II & $\log (V)=1.245 \log (A)-1.008$ & 42 & 0.81 \\
III & $\log (V)=1.3387 \log (A)-1.6563$ & 27 & 0.89 \\
\hline
\end{tabular}
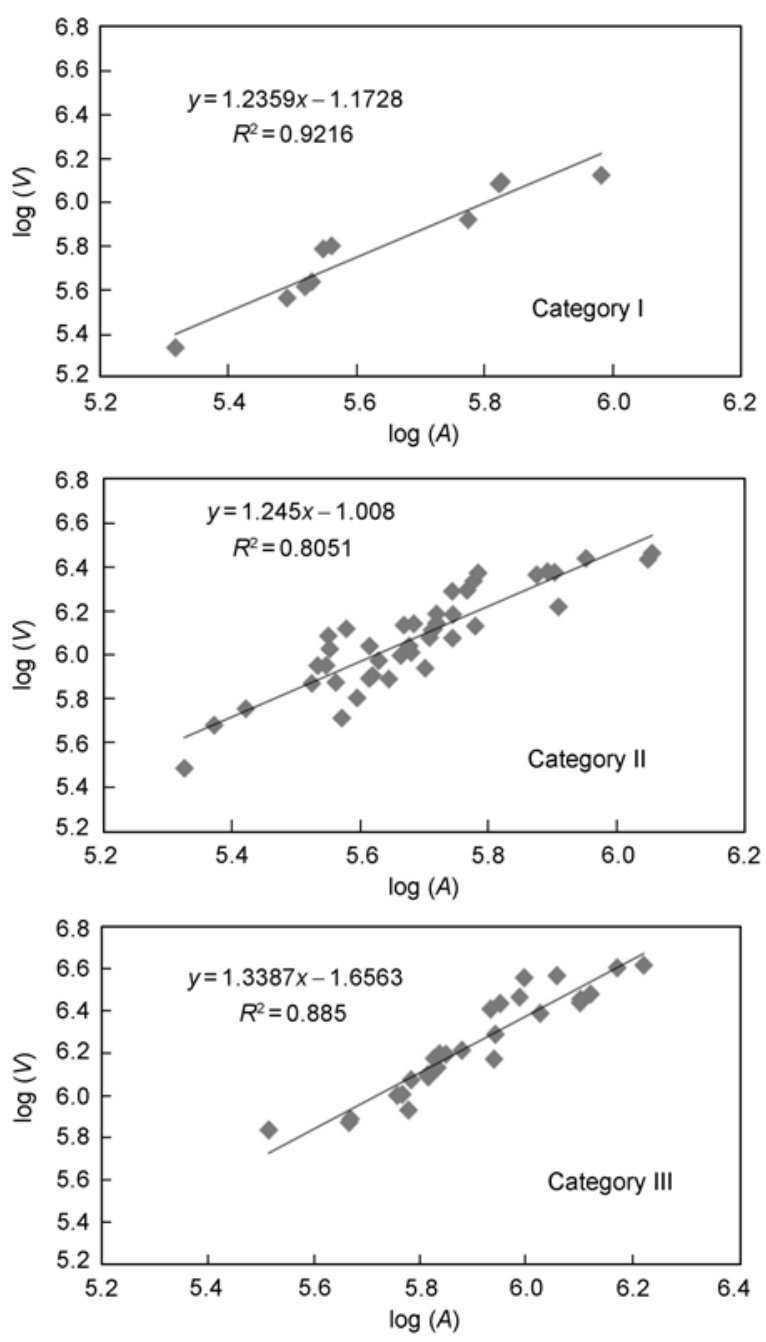

图 4 各类小水库面积库容相关关系散点图

完整的汛期中, 并且相对应的小水库运行资料较全, 因此选择该时段进行小水库拦洪计算，计算结果见 表 5. 可以看出, 对于 20060826 洪水, 19 个小水库的 实测拦洪量为 158.3 万 $\mathrm{m}^{3}$, 使用本文的方法计算得拦 洪量 158.1 万 $\mathrm{m}^{3}$, 绝对误差为 -0.2 万 $\mathrm{m}^{3}$, 相对误差为 $-0.12 \%$, 模拟精度较高.

\section{4 考虑水利工程拦蓄的洪水预报方案校正} 本节通过计算水利工程对 20060826 洪水的拦洪

表 5 小水库拦洪计算验证(单位: 万 $\mathbf{m}^{\mathbf{3}}$ )

\begin{tabular}{cccccccc}
\hline Flood number & Start date & End date & $\begin{array}{c}\text { The number of small } \\
\text { reservoirs calculated }\end{array}$ & $\begin{array}{c}\text { Measured flood } \\
\text { detention quantity }\end{array}$ & $\begin{array}{c}\text { Simulated flood } \\
\text { detention quantity }\end{array}$ & $\begin{array}{c}\text { Absolute } \\
\text { error }\end{array}$ & $\begin{array}{c}\text { Relative } \\
\text { error }(\%)\end{array}$ \\
\hline 20060826 & $2006-8-26$ & $2006-9-8$ & 19 & 158.3 & 158.1 & -0.2 & -0.12 \\
\hline
\end{tabular}


量, 校正原有的洪水预报结果. 计算拦洪量时大中型 水库的拦洪量由实测资料推求, 小水库塘坝的拦洪 量采用本文所用方法计算.

\subsection{1 水利工程的拦洪量计算}

对遥感数据提取的水体信息进行处理, 采用掩 膜法剔除大中型水库及河道信息, 可得小水库塘坝 的面积信息, 采用上述拦洪计算方法便可得出小水 库塘坝的拦洪量. 由于研究流域位于 4 个轨道遥感图 像的交界处，不能得到全流域同一时间的水面面积， 因此本文仍以轨道号为 $\mathrm{p} 118 \mathrm{r} 30$ 的遥感数据覆盖范围 为研究重点, 挖掘出小水库塘坝的拦洪规律, 再推广 到全流域.

由图 1 可知, 研究范围内有东丰、磐石两个水文 站, 其上游小水库塘坝总库容分别为 2855 万 $\mathrm{m}^{3}$ 与 3681 万 $\mathrm{m}^{3}$. 通过计算可得东丰、磐石水文站上游的 小水库塘坝的拦洪量, 将此拦洪量除以总库容得到 两个控制站的拦洪比, 再将其平均拦洪比作为全流 域的拦洪比, 乘以全流域小水库塘坝总库容得到全 流域所有小水库塘坝的总拦洪量. 小水库塘坝的平 均拦洪比计算结果如表 6 所示, 各类水利工程的拦洪 量见表 7, 其中大中型水库拦洪量由实测资料计算.

\subsection{2 考虑水利工程拦蓄的洪水预报校正}

丰满 II 区原有的洪水预报方法为降雨径流相关
图法 ${ }^{[28], ~}$ 用表 7 计算的拦洪量校正原预报方案, 结果 如表 8 所示. 可以看出, 20060826 洪水的洪水总量为 2.02 亿 $\mathrm{m}^{3}$, 原洪水预报方案的预报值为 2.67 亿 $\mathrm{m}^{3}$, 相对误差为 $31.8 \%$, 校正后的洪量为 2.23 亿 $\mathrm{m}^{3}$, 相对 误差减少到 $10.1 \%$.

\section{6 结论与展望}

本文初步尝试将遥感数据与传统的水文数据结 合, 提出了基于遥感数据的小水库拦洪计算方法, 并 将其应用于丰满 II 区流域, 得出以下结论.

1) “Landsat TM/ETM+”数据空间分辨率较高, 适用于小水库塘坝水面信息的提取. 但数据精度受 云层的影响较大, 导致汗期缺少数据样本, 影响拦洪 计算. 若采用受云层影响较小的高精度的雷达数据 进行分析，便可克服这一缺陷;

2) 三类小水库的面积库容相关关系较好, $R^{2}$ 均 在 0.8 以上，说明以子流域平均坡度为标准的小水库 分类方法可行，且该相关关系也可用于与丰满 II 区 地形条件相似的其它流域;

3) 针对 20060826 洪水, 对 19 个有资料小水库 进行拦洪计算发现，拦洪总量绝对误差 -0.2 万 $\mathrm{m}^{3}$, 相对误差 $-0.12 \%$;

4) 计算得到全流域水利工程对 20060826 洪水 的拦洪量为 4389.6 万 $\mathrm{m}^{3}$, 采用该值校正原洪水预报

表 6

小水库塘坝平均拦洪比计算表

\begin{tabular}{cccc}
\hline & $\begin{array}{c}P \\
(\mathrm{~mm})\end{array}$ & $\begin{array}{c}\text { Flood detention } \\
\text { quantity }\left(10^{4} \mathrm{~m}^{3}\right)\end{array}$ & $\begin{array}{c}\text { Total capacity of ponds and } \\
\text { small reservoirs }\left(10^{4} \mathrm{~m}^{3}\right)\end{array}$ \\
\hline Upstream area of Dongfeng station & 66.3 & 56.92 & 2855 \\
Upstream area of Panshi station & 67.9 & 275.7 & 3681 \\
Average flood detention ratio & & & 7.99 \\
\hline
\end{tabular}

表 7 水利工程对 20060826 洪水的拦洪量(单位：万 $\mathbf{m}^{3}$ )

\begin{tabular}{|c|c|c|c|c|c|}
\hline \multicolumn{3}{|c|}{ Flood detention quantity calculation of ponds and small reservoirs } & \multirow{2}{*}{$\begin{array}{c}\text { Flood detention } \\
\text { quantity of mid-sized } \\
\text { reservoirs }\end{array}$} & \multirow{2}{*}{$\begin{array}{l}\text { Flood detention } \\
\text { quantity of large } \\
\text { reservoirs }\end{array}$} & \multirow{2}{*}{$\begin{array}{c}\text { Total flood } \\
\text { detention } \\
\text { quantity }\end{array}$} \\
\hline $\begin{array}{l}\text { Average flood detention } \\
\text { ratio }(\%)\end{array}$ & $\begin{array}{c}\text { Total } \\
\text { capacity }\end{array}$ & $\begin{array}{l}\text { Flood detention } \\
\text { quantity }\end{array}$ & & & \\
\hline 4.74 & 46231 & 2190.9 & 1582.7 & 616 & 4389.6 \\
\hline
\end{tabular}

表 8 考虑水利工程拦蓄的 20060826 洪水预报方案校正

\begin{tabular}{ccccccccccccc}
\hline $\begin{array}{c}\text { Measured flood } \\
\text { quantity } \\
\left(10^{4} \mathrm{~m}^{3}\right)\end{array}$ & $\begin{array}{c}P \\
(\mathrm{~mm})\end{array}$ & $\begin{array}{c}P a \\
(\mathrm{~mm})\end{array}$ & $\begin{array}{c}P+P a \\
(\mathrm{~mm})\end{array}$ & $\begin{array}{c}R \\
(\mathrm{~mm})\end{array}$ & $\begin{array}{c}\text { Basin area } \\
\left(\mathrm{km}^{2}\right)\end{array}$ & $\begin{array}{c}\text { Forecast } \\
\text { quantity } \\
\left(10^{4} \mathrm{~m}^{3}\right)\end{array}$ & $\begin{array}{c}\text { Relative } \\
\text { error } \\
(\%)\end{array}$ & $\begin{array}{c}\text { Detention } \\
\text { quantity } \\
\left(10^{4} \mathrm{~m}^{3}\right)\end{array}$ & $\begin{array}{c}\text { Quantity after } \\
\text { adjustment } \\
\left(10^{4} \mathrm{~m}^{3}\right)\end{array}$ & $\begin{array}{c}\text { Relative } \\
\text { error } \\
(\%)\end{array}$ \\
\hline 20236.6 & 73.8 & 37.5 & 111.3 & 23 & 11600 & 26680 & 31.8 & 4389.6 & 22290.4 \\
\hline
\end{tabular}


方案, 校正后的相对误差由校正前的 $31.8 \%$ 降低到 $10.1 \%$.

由上述结论可知，本文提出的计算方法能够反 映小水库塘坝对洪水的拦蓄作用, 但部分计算过程 可能存在误差, 其对计算结果的影响还有待进一步
研究. 另一方面, 该方法只能在已知两景遥感数据的 前提下计算小水库塘坝的蓄泄过程, 在进行实时预 报校正方面还存在一定的问题. 如何利用单景遥感 数据并结合水文气象资料推求小水库塘坝的蓄泄规 律, 也有待进一步研究.

\section{参考文献}

1 贾仰文, 王浩. “黄河流域水资源演变规律与二元演化模型”研究成果简介. 水利水电技术, 2006, 37(2): 45-52

2 Jia Y W, Wang H, Zhou Z H, et al. Development of the WEP-L distributed hydrological model and dynamic assessment of water resources in the Yellow River basin. J Hydrol, 2006, 331: 606-629

3 王浩, 王成明, 王建华, 等. 二元年径流演化模式及其在无定河流域的应用. 中国科学 E 辑: 技术科学, 2004, 34(Suppl): 42-48

4 贾仰文, 王浩, 严登华. 黑河流域水循环系统的分布式模拟 ( I )一模型开发与验证. 水利学报, 2006, 37(5): 534-542

5 Ren L L, Wang M R, Li C H, et al. Impacts of human activity on river runoff in the northern area of China. J Hydrol, 2002, 261: 204-217

$6 \mathrm{Xu} \mathrm{J} \mathrm{J}$, Yang D W, Yi Y H, et al. Spatial and temporal variation of runoff in the Yangtze River basin during the past 40 years. Quatern Int, 2008, 186: 32-42

7 任立良, 张炜, 李春红, 等. 中国北方地区人类活动对地表水资源的影响研究. 河海大学学报(自然科学版), 2001, 29(4): 13-18

8 黄强, 蒋晓辉, 刘俊萍, 等. 二元模式下黄河年径流变化规律研究. 自然科学进展, 2002, 12(8): 874-877

9 刘红玉, 李兆富. 三江平原典型湿地流域水文情势变化过程及其影响因素分析. 自然资源学报, 2005, 20(4): 494-501

10 Barlage M J, Richards P L, Sousounis P J, et al. Impacts of climate change and land use change on runoff from a Great Lakes watershed. J Great Lakes Res, 2002, 28(4): 568-582

11 Seguis L, Cappelaere B, Milesi G, et al. Simulated impacts of climate change and land-clearing on runoff from a small Sahelian catchment. Hydrol Process, 2004, 18(17): 3401-3413

12 Zhao F F, Xu Z X, Zhang L, et al. Streamflow response to climate variability and human activities in the upper catchment of the Yellow river basin. Sci China Ser E-Tech Sci, 2009, 52: 3249-3256

13 Pinter N, Ickes B S, Wlosinski J H, et al. Trends in flood stages: contrasting results from the Mississippi and Rhine river systems. J Hydrol, 2006, 331: 554-566

14 Brath A, Montanari A, Moretti G. Assessing the effect on flood frequency of land use change via hydrological simulation. J Hydrol, 2006, 324(1): 141-153

15 程春田, 王本德. 考虑人类活动影响的流域水文模型参数的确定. 大连理工大学学报, 1995, 35(3): 400-404

16 郭生练, 王金星, 彭辉, 等. 考虑人类活动影响的丰满水库洪水预报方案. 水电能源科学, 2000, 18(2): 14-17

17 Monteith J L. Evaporation and environment. Symp Soc Exp Biol, 1965, 19: 205-234

18 Liebe J, van de Giesen N, Andreini M. Estimation of small reservoir storage capacities in a semi-arid environment: A case study in the upper east region of Ghana. Phys Chem Earth, 2005, 30(6): 448-454

19 丁智雄. DEM 与遥感相结合的水库水位面积曲线测定方法研究. 水利水电技术, 2010, 41(1): 83-86

20 Du Y Y, Zhou C H. Automatically extracting remote sensing information for water bodies. J Remot Sens, 1988, 2(4): 264-269

21 曹波. 基于遥感图像和 DEM 测定水库动库容的方法研究. 武汉: 华中科技大学, 2006

22 吴赛. 基于 EOS/MODIS 的水体提取模型及其在洪灾监测中的应用. 武汉: 华中科技大学, 2005

23 李永生, 武鹏飞. 基于 MODIS 数据的艾比湖湖面变化研究. 水资源与水工程学报, 2008, 19(5): 110-112

24 Mcfeeters S K. The use of the normalized difference water index (NDWI) in the delineation of open water features. Int J Remot Sens, 1996, 17(7): 1425-1432

25 Gao B C. NDWI-A normalized difference water index for remote sensing of vegetation liquid water from space. Remot Sens Environ, 1995, 58: $257-266$

26 Ouma Y, Tateishi R. A water index for rapid mapping of shoreline changes of five east african rift valley lakes: An empirical analysis using Landsat TM and ETM+ data. Int J Remot Sens, 2006, 27(15): 3153-3181

27 Sawunyama T, Senzanje A, Mhizha A. Estimation of small reservoir storage capacities in Limpopo River Basin using geographical information systems (GIS) and remotely sensed surface areas case of Mzingwane catchment. Phys Chem Earth, 2006, 31(15): 935-943

28 水利部松辽水利委员会. 东北地区实用洪水预报方案(上册). 1993 